\title{
Validation of the poke-flow technique combined with simulations of fluid flow for determining viscosities in samples with small volumes and high viscosities
}

\author{
J. W. Grayson ${ }^{1, *}$, M. Song ${ }^{1, *}$, M. Sellier ${ }^{2}$, and A. K. Bertram ${ }^{1}$ \\ ${ }^{1}$ Department of Chemistry, University of British Columbia, Vancouver, BC V6T 1Z1, Canada \\ ${ }^{2}$ Department of Mechanical Engineering, University of Canterbury, Christchurch 8140, New Zealand \\ *These authors contributed equally to this work.
}

Correspondence to: A. K. Bertram (bertram@chem.ubc.ca)

Received: 21 November 2014 - Published in Atmos. Meas. Tech. Discuss.: 23 January 2015

Revised: 8 May 2015 - Accepted: 22 May 2015 - Published: 16 June 2015

\begin{abstract}
Viscosity in particles consisting of secondary organic material (SOM) has recently become an area of research focus, since information on viscosity is needed to predict the environmental impacts of SOM particles. Recently Renbaum-Wolff et al. (2013a) developed a poke-flow technique that was combined with simulations of fluid flow to constrain the viscosities of SOM samples of 1-5 mg mass, roughly the maximum that may be collected from environmental chambers or flow tubes on a reasonable timescale. The current manuscript expands on the initial validation experiments carried out by Renbaum-Wolff et al. First, the poke-flow technique combined with simulations of fluid flow was used to determine the viscosity of sucrose-water particles over a relatively wide range of relative humidities (RHs). The lower and upper limits of viscosity at $59 \% \mathrm{RH}$ were $1.0 \times 10^{1}$ and $1.6 \times 10^{4} \mathrm{Pas}$, whilst at $37 \% \mathrm{RH}$ the corresponding values were $7.2 \times 10^{4}$ and $4.7 \times 10^{6} \mathrm{~Pa} \mathrm{~s}$, respectively. The results are in good agreement with recent measurements by Quintas et al. (2006) and Power et al. (2013). Second, the approach was used to determine the viscosity of two polybutene standards. The simulated lower and upper limits of viscosity for standard \#1 was $2.0 \times 10^{2}$ and $1.2 \times 10^{4} \mathrm{~Pa}$ s, whilst for standard \#2 the corresponding values were $3.1 \times 10^{2}$ and $2.4 \times 10^{4} \mathrm{Pas}$. These values are in good agreement with values reported by the manufacturer. The results for both the sucrose-water particles and the polybutene standards show that the poke-flow technique combined with simulations of fluid flow is capable of providing both lower and upper limits of viscosity that are consistent
\end{abstract}

with literature or measured values when the viscosity of the particles are in the range of $\approx 5 \times 10^{2}$ to $\approx 3 \times 10^{6} \mathrm{~Pa}$.

\section{Introduction}

Particles consisting of secondary organic material (SOM) are abundant in the atmosphere and, depending upon location, typically account for $20-80 \%$ of the mass of atmospheric aerosol particles (Kanakidou et al., 2005; Jimenez et al., 2009). These SOM particles can affect the Earth's climate directly by scattering and/or absorbing solar radiation and indirectly by acting as ice and liquid cloud droplet nuclei (Solomon et al., 2007; Murray et al., 2010; Wang et al., 2012). In addition, SOM particles can influence air quality and human health (Jang et al., 2006; Baltensperger et al., 2008).

Knowledge of diffusion rates of organics within SOM particles is important for determining rates of particle growth, rates of heterogeneous reactions and long-range transport of pollutants (Koop et al., 2011; Riipinen et al., 2011; Shiraiwa et al., 2011; Kuwata and Martin, 2012; Perraud et al., 2012; Riipinen et al., 2012; Shiraiwa and Seinfeld, 2012; Zelenyuk et al., 2012; Shiraiwa et al., 2013; Zhou et al., 2013). For example, Riipinen et al. (2011) showed that the size distribution and number concentrations of ultrafine aerosol particles, which are important for the aerosol direct and indirect effect on climate, depend on diffusion within particles. Shiraiwa and Seinfeld (2012) showed that predictions of the total mass 
of SOM particles in urban environments are sensitive to diffusion coefficients of organics in the SOM material, and Shiraiwa et al. (2011) showed the chemical aging of semisolid SOM can depend on the rate of molecular diffusion of organics within the particle. In addition, Zelenyuk et al. (2012) demonstrated that transportation of polycyclic aromatic hydrocarbons (PAHs) in the atmosphere can depend on diffusion rates in particles.

Diffusion rates of organics in SOM particles can be estimated using viscosity measurements and the Stokes-Einstein relation, and, as such, measurements of viscosity in SOM particles have recently become an area of research focus. The viscosity, $\eta$, of SOM may span multiple orders of magnitude, from $10^{-3}$ to $>10^{12} \mathrm{~Pa} \mathrm{~s}$, across the ambient relative humidity $(\mathrm{RH})$ range in the atmosphere through the uptake and release of water (Koop et al., 2011; Kuwata and Martin, 2012; Renbaum-Wolff et al., 2013a). Measuring such a wide range of viscosities presents a challenge, made more difficult by the small, milligram, scale of SOM samples typically collected in the atmosphere or chambers used to simulate atmospheric conditions. Currently, there is no commercially available technique capable of quantifying the viscosity of SOM samples across the entire viscosity range important in the atmosphere. However, a few techniques have recently been developed, each of which is capable of covering at least part of the range of interest.

Renbaum-Wolff et al. (2013b) developed a bead-mobility technique, which can determine the viscosities of SOM samples with masses between 1 and $5 \mathrm{mg}$ and viscosities between $10^{-3}$ and $10^{3} \mathrm{Pas}$. This technique consists of determining the speed of circulation of micrometer-sized beads within a particle as a shear stress is applied to the particle. In a subsequent paper, Renbaum-Wolff et al. (2013a) developed a poke-flow technique that was combined with simulations of fluid flow to constrain the viscosities of SOM samples of 1$5 \mathrm{mg}$ mass. The technique consisted of generating a hole in a supermicron-sized SOM particle suspended on a surface and determining a characteristic time taken for the hole to close. Simulations of fluid flow were subsequently performed to determine limits for the viscosity of the particle, based upon the time taken for the hole at its centre to close. RenbaumWolff et al. (2013a) demonstrated that measured upper limits of viscosity were consistent with literature values up to at least $10^{4} \mathrm{~Pa}$.

Power et al. (2013) used holographic optical tweezers to coalesce two suspended particles with a combined volume of $<500$ femtolitres. By measuring the time taken for the resulting particle to relax to a spherical shape, viscosities of sucrose-water or sucrose-salt-water particles were quantified across the range of $10^{-3}-10^{9} \mathrm{~Pa}$. Subsequently, Power and Reid (2014) further outlined the application of optical tweezers for rheological measurements. In a similar vein, Pajunoja et al. (2014) used scanning electron microscopy images to determine the viscosity of secondary organic aerosols by studying the time taken for multiple particles to coalesce.
Hosny et al. (2013) observed the behaviour of molecular rotors using fluorescence lifetime imaging microscopy to determine the viscosity of sodium chloride and sucrose-water particles. In addition, Kidd et al. (2014) estimated some limits to viscosities of particles from the extent to which material collected in the centreline of an impactor spreads under high airflow.

In the paper by Renbaum-Wolff et al. (2013a), only a preliminary validation of the poke-flow technique combined with simulations of fluid flow was carried out for viscosities $<10^{8} \mathrm{~Pa}$ s due to the lack of suitable standards for validation at the time of publication. Specifically, Renbaum-Wolff et al. used sucrose-water particles over a narrow range of RHs to validate the approach for viscosities $<10^{8} \mathrm{~Pa}$. In addition, as mentioned above, for viscosities $<10^{8} \mathrm{Pas}$, the authors only showed that the approach was able to provide upper limits to the viscosity of the particles. No attempt was made to determine lower limits to the particle viscosity using the poke-flow technique combined with simulations of fluid flow when the viscosity was $<10^{8} \mathrm{~Pa}$.

In the following study we expand on the initial validation and characterization of the poke-flow technique combined with simulations of fluid flow. First, the approach is used to determine the viscosity of sucrose-water particles over a wider range of RHs than previously done by Renbaum-Wolff et al. (2013a). These results are compared to recent results published by Power et al. (2013), who reported viscosities of sucrose-water particles ranging from $10^{-3}$ to $10^{9} \mathrm{~Pa} \mathrm{~s}$, and Quintas et al. (2006), who measured a viscosity of $10^{3} \mathrm{~Pa}$ s at $54 \% \mathrm{RH}$ using a rotational controlled stress rheometer. Second, the approach was used to determine the viscosity of two polybutene standards, and the results were compared with viscosities measured by the manufacturer using a commercially available viscometer. The results for both the sucrosewater particles and the polybutene standards show that this approach is capable of providing both lower and upper limits of viscosity that are consistent with literature or measured values for particles of material that range in viscosity from $\approx 5 \times 10^{2}$ to $\approx 3 \times 10^{6} \mathrm{Pas}$.

\section{Materials and methods}

\subsection{Poke-flow technique}

The qualitative method of poking a particle to determine the particle phase (i.e. solid/semisolid vs. liquid) was introduced by Murray et al. (2012). This approach was expanded upon by Renbaum-Wolff et al. (2013a) by quantifying flow rates after poking and determining viscosities from simulations of flow. Figure 1 illustrates schematically the experimental setup for the poke-flow measurements. First supermicron particles of interest (either particles containing sucrose-water or polybutene standards) were deposited on a hydrophobic glass substrate $(18 \mathrm{~mm}$ diameter) (Hampton 


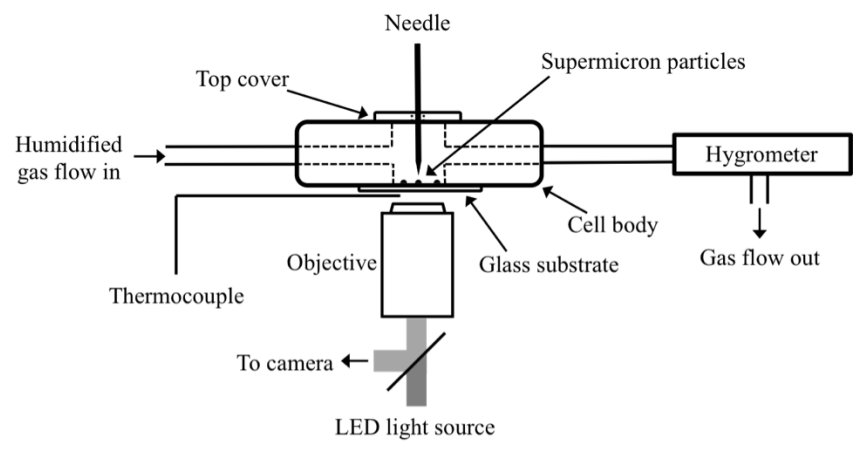

Figure 1. Schematic representation of poke-flow experimental setup.

Research, Canada). The glass substrate was then mounted onto a custom-made flow cell, similar to those described previously (Koop et al., 2000; Song et al., 2012; You et al., 2012) but with a small hole added at the top through which a needle could be inserted (Renbaum-Wolff et al., 2013a). RH within the cell was controlled through the use of humidified ultrapure $\mathrm{N}_{2}$ gas, a stream of which was flowed continuously through the cell. Gas flow was maintained at $1200 \mathrm{sccm}$ for all experiments. The dew point temperature of the humidified $\mathrm{N}_{2}$ gas was measured at the outflow of the cell using a hygrometer with a chilled-mirror sensor (General Eastern, Canada). The hygrometer was calibrated prior to experiments being performed by determining the deliquescence relative humidity (DRH) of ammonium sulfate particles and comparing the observed DRH value to that in the literature $(\approx 80.3 \%$ $\mathrm{RH}$ at $\left.20^{\circ} \mathrm{C}\right)$. The uncertainty $(1 \sigma)$ of the hygrometer was \pm 0.5 at $80.3 \% \mathrm{RH}$ after calibration. The temperature of the sample was measured directly below the flow cell using a thermocouple. Particles were monitored during experiments using a reflectance optical microscope (Zeiss Axio Observer, $40 \times$ objective) and recorded using a CCD camera.

Two different types of needles were used for experiments. For particles of low viscosity, a sterilized sharp needle $(0.9 \mathrm{~mm} \times 40 \mathrm{~mm})$ (Becton-Dickson, USA) was used. However, at higher viscosity particles stuck to the needle and as a result were removed from the substrate. As such, a second set of needles was used (RS-6063, Roboz Surgical Instrument Co., USA), which were coated with a hydrophobic Dursan coating (SilcoTek, USA) to prevent material sticking to the needles. The needles were mounted to a micromanipulator (Narishige, model MO-202U, Japan) and inserted through the hole at the top of the flow cell. The effect of the presence of the hole at the top of the flow cell upon $\mathrm{RH}$ in the cell was determined to be minimal by studying the DRH of ammonium sulfate and potassium carbonate particles with the hole open and the hole closed. The DRH of ammonium sulfate particles differed by $<0.2$ at $80 \% \mathrm{RH}$, whilst the DRH of potassium carbonate particles differed by $<0.4$ at $43 \% \mathrm{RH}$.
The micromanipulator was used to move the needle in the $x$, $y$, and $z$ axes.

For a given experiment, the tip of the needle was aligned vertically above the centre of a particle and then moved down in the $z$ direction, first penetrating the particle at the peak of its spherical cap geometry and subsequently coming in contact with the substrate beneath. After the needle was removed, the material of the particle was present in a nonequilibrium half-torus geometry and began to flow in order to minimize the surface energy of the system. Eventually the hole at the centre of the half torus completely closed, and the particle returned to its original spherical cap morphology.

Analysis of optical images captured during each experiment was performed using Zen software (Zeiss). The hole at the centre of the half torus was traced and the area of the hole calculated. An equivalent area diameter of the hole was calculated via the relationship $d=(4 A / \pi)^{1 / 2}$, where $d$ is the equivalent area diameter of a hole of area, $A$ (Reist, 1992). The experimental flow time, termed $\tau_{\text {exp, flow, was assigned }}$ as the time taken for the equivalent area diameter to decrease to $50 \%$ of its original value. This definition of experimental flow time was chosen as it allows experimental flow time of more viscous particles, the holes of which may not fully close on a laboratory timescale, to be measured.

In some of the experiments, a point around the inner edge of the half torus appeared to be pinned to the hydrophobic surface. This behaviour may suggest that in some cases the needle scratched the surface. Particles that exhibited this pinning behaviour were excluded from analysis in order to avoid influencing the results. Pinning affected $<20 \%$ of all the particles that formed a torus geometry after poking.

Sucrose-water particles were produced on siliconized hydrophobic glass substrates using a nebulizer (Meinhard; product no. TR-50-A1). First sucrose (Sigma-Aldrich, purity $>99.5 \%$ ) was combined with high-purity water (Millipore, $18.2 \mathrm{M} \Omega \mathrm{cm}$ ) to produce an aqueous solution. The solution was then nebulized to produce submicron-sized particles, which subsequently coagulated on the substrate to form supermicron-sized particles, $25-60 \mu \mathrm{m}$ in diameter. In the sucrose-water experiments, particles were allowed to equilibrate at a given RH for 30-60 min prior to being poked, which, given their size and approximate viscosity, was sufficient time for the particles to have a water content in equilibrium with that of the gas flowing through the cell (Shiraiwa, 2011; Price et al., 2014).

Particles consisting of polybutene standards (N450000 and N2700000; Cannon Instrument Company, USA) were prepared on hydrophobic glass substrates using a pipette. The samples were heated to $60-70{ }^{\circ} \mathrm{C}$ over $\approx 30 \mathrm{~min}$ to aid the production of particles by reducing the viscosity of the material, with material being picked up on a pipette tip and the pipette being "flicked" towards the substrate, resulting in particles being formed on the substrate. After particle production, the particles were allowed to equilibrate at dry $(<0.5 \%$ $\mathrm{RH}$ ) conditions at room temperature for $60 \mathrm{~min}$. Particles 


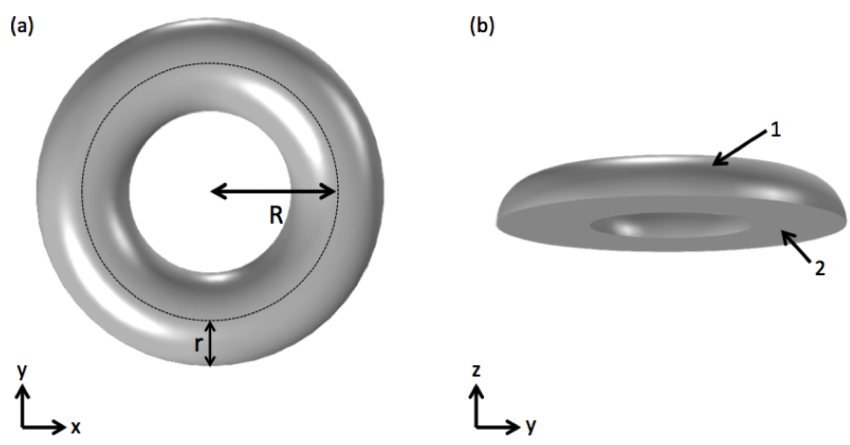

Figure 2. Details of half-torus model used to simulate the flow in experiments: (a) top view, where $R$ and $r$ are the notations used here to describe the dimensions of a half-torus geometry; (b) side view, where surface 1 represents the air-fluid interface, and surface 2 represents the fluid-substrate interface.

consisting of polybutene standards that were poked ranged in diameter from 40 to $70 \mu \mathrm{m}$.

\subsection{Simulations of fluid flow}

Flow in the poke-flow experiments was simulated using the laminar two-phase flow, moving mesh mode within the micro-fluidics module of COMSOL (version 4.3a), a finite-element analysis software package. The Navier-Stokes equation, including surface tension, is used to describe the transport of mass and momentum, whilst the arbitrary Lagrangian-Eularian (ALE) method is used to track the evolution of the fluid over time as it flows to attain a spherical cap geometry and thus minimize the surface energy of the system. Simulations were performed with a mesh that consisted of $\approx 5800$ elements and had a mesh spacing of 3.92$337 \mathrm{~nm}$.

A top view of the half-torus geometry used to simulate the experimental observations is shown in Fig. 2a, where the dotted line is at the midpoint between the inner and outer edges of the ring of material forming the torus. The initial radius of the hole at the centre of the half torus is denoted as $R_{0}$ $r_{0}$, where $R_{0}$ represents the distance from the centre of the hole to the midpoint of the ring of material that creates the torus, whilst $r_{0}$ represents the radius of the ring of material. The half torus had two distinct surfaces (Fig. 2b). Surface 1 represents the air-fluid interface, which was allowed to undergo free deformation in all dimensions. Surface 2 is the fluid-substrate interface, which was allowed to undergo free deformation in the horizontal $x-y$ plane, but not in the vertical, $z$, direction. In the simulations, the size of the hole in the half-torus geometry decreases in an axi-symmetric manner. The time taken for $R_{0}-r_{0}$ to decrease to $50 \%$ of the initial value was assigned $\tau_{\text {model, flow }}$.

The values of certain physical properties could be defined for a given simulation. The dimensions $R_{0}$ and $r_{0}$, and the equilibrium contact angle were determined from measure- ments, and the values of surface tension (Surface 1, Fig. 2b), slip length (which describes the interaction at Surface 2 in Fig. 2b), and the density of the material were determined based on literature values. These values are detailed in Tables 1 and 2. For each particle that was poked and formed a half-torus geometry, and was not significantly influenced by scratches (determined visually, as discussed above), lower and upper limits of viscosity were determined via simulations. The dimensions of the particle $\left(R_{0}\right.$ and $\left.r_{0}\right)$ were used, as were the relevant parameters in Table 1 (for particles of sucrose-water) or Table 2 (for particles of polybutene standards). Values from row 2 of Tables 1 and 2 were used for simulations of the lower limit of viscosity for a particle, whilst values from row 3 of Tables 1 and 2 were used for simulations of its upper limit of viscosity. The viscosity used in the simulations of a particle was varied until $\tau_{\text {model, flow }}$ agreed with the particles $\tau_{\text {exp, flow }}$ (to within $1 \%$ ).

A proportion $(\approx 30 \%)$ of the sucrose-water particles that were poked had dimensions where $r_{0} / R_{0}>\approx 0.4$. Simulations of the lower limit of viscosity for many of these particles gave rise to a non-physical geometry whereby the inner edge of the half torus geometry appeared jagged and wavy - a phenomenon not observed during experiments. Further study of this phenomenon revealed that this was the result of the stretching of the mesh elements at the moving front of the particle, and use of a finer mesh did not prevent this from occurring. As such, all sucrose-water particles of dimensions $r_{0} / R_{0}>\approx 0.4$ were removed from the study. No particles of the polybutene standard fell into this size range.

\section{Results and discussion}

\subsection{Sucrose-water particles}

Shown in Fig. 3 are examples of optical images of sucrosewater particles at $48.8,52.7$, and $58.8 \% \mathrm{RH}$ recorded during typical poke-flow experiments. Prior to being poked the particles may be described geometrically as a spherical cap (Fig. 3a1, b1 and c1). Just after being poked the geometry of the particles can be described as a half torus - a ring of material with a hole at its centre (Fig. 3a2, b2, and c2), which is energetically unfavourable compared to that of a spherical cap. For the particles in Fig. 3 , $\tau_{\text {exp, flow }}$ was determined to be $11.25,3.75$, and $1.25 \mathrm{~s}$ at $48.8,52.7$, and $58.8 \% \mathrm{RH}$, respectively (Fig. 3a3, b3, and c3). Following $\tau_{\text {exp } \text {, flow the material }}$ continued to flow, and eventually re-attained its initial, energetically favourable, spherical cap geometry (Fig. 3a4, b4, and $\mathrm{c} 4)$.

The $\tau_{\text {exp, flow }}$ values of each of the individual sucrosewater particles poked and analysed is shown in Fig. 4a. Experimental flow times increased from $\approx 150 \mathrm{~ms}$ at $59 \% \mathrm{RH}$ to $\approx 40 \mathrm{~min}$ at $37 \% \mathrm{RH}$. The millisecond time resolution of the camera precluded experiments being performed at $\mathrm{RH}>60 \%$ as the closure time for the sucrose-water par- 


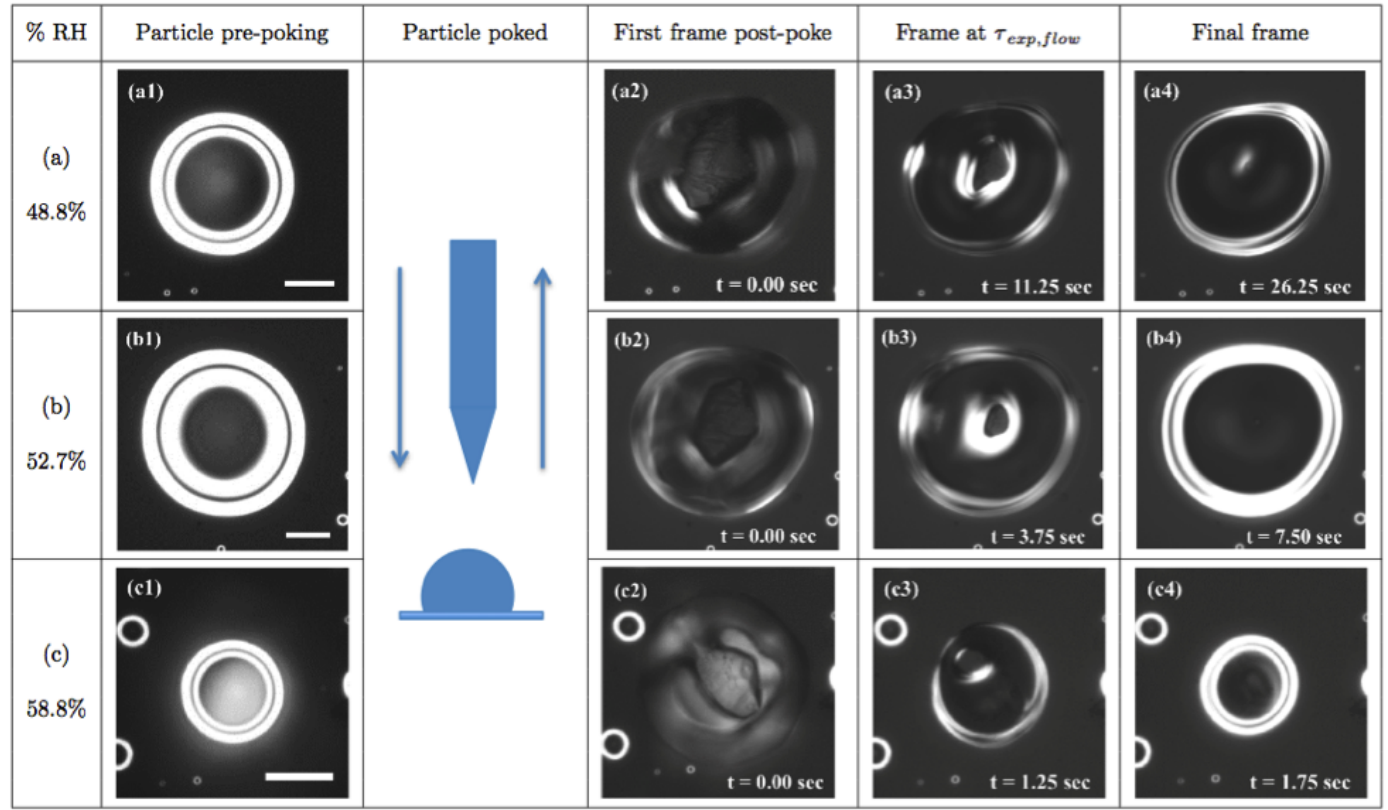

Figure 3. Optical images of sucrose-water particles poked at RHs of (a) 48.8, (b) 52.7, and (c) $58.8 \%$ recorded during typical poke-flow experiments. Images a1, b1, and $\mathrm{c} 1$ correspond to the particles before they are poked. Images a2, b2, and c2 correspond to the first frame post-poke (i.e. the first frame after the needle has been removed). Images a3, b3, and c3 correspond to images of the experimental flow time, $\tau_{\exp \text {, flow }}$, the point at which the equivalent area diameter of the hole at the centre of the particle has decreased to $50 \%$ of its original size. Images a4, b4, and c4 correspond to the final frame recorded, at which point each particle has re-attained its original spherical cap geometry. Scale bar: $20 \mu \mathrm{m}$.

Table 1. Experimental parameters used when simulating flow with COMSOL for the sucrose-water experiments.

\begin{tabular}{lllll}
\hline & $\begin{array}{l}\text { Surface tension } \\
\left(\mathrm{mN} \mathrm{m}^{-1}\right)\end{array}$ & $\begin{array}{l}\text { Slip length } \\
(\mathrm{m})\end{array}$ & $\begin{array}{l}\text { Density } \\
\left(\mathrm{kg} \mathrm{m}^{-3}\right)\end{array}$ & $\begin{array}{l}\text { Contact angle } \\
\left({ }^{\circ}\right)\end{array}$ \\
\hline Range of values & $57.2-75.15^{\mathrm{a}}$ & $\begin{array}{l}5 \times 10^{-9}- \\
1 \times 10^{-5^{\mathrm{b}}}\end{array}$ & $\begin{array}{l}1490- \\
1520^{\mathrm{c}}\end{array}$ & $94.8-102.2^{\mathrm{d}}$ \\
\hline $\begin{array}{l}\text { Value used to calculate } \\
\text { lower limit of viscosity }\end{array}$ & 57.2 & $5 \times 10^{-9}$ & 1500 & $\begin{array}{l}94.8 \text { for particles of }\left(R_{0}-r_{0}\right) / r_{0}<2 \\
102.2 \text { for particles of }\left(R_{0}-r_{0}\right) / r_{0}>2\end{array}$ \\
\hline $\begin{array}{l}\text { Value used to calculate } \\
\text { upper limit of viscosity }\end{array}$ & 75.15 & $1 \times 10^{-5}$ & 1500 & $\begin{array}{l}102.2 \text { for particles of }\left(R_{0}-r_{0}\right) / r_{0}<2 \\
94.8 \text { for particles of }\left(R_{0}-r_{0}\right) / r_{0}>2\end{array}$ \\
\hline
\end{tabular}

${ }^{a}$ Power et al. (2013), MacDonald et al. (1996). ${ }^{\mathrm{b}}$ This range is based on experimental measurements of the slip length of water and organic compounds on hydrophobic surfaces (Schnell, 1956; Churaev et al., 1984; Watanabe and Udagawa, 1999; Baudry et al., 2001; Craig et al., 2001; Tretheway and Meinhart, 2002; Cheng and Giordano, 2002; Jin et al., 2004; Joseph and Tabeling, 2005; Neto et al., 2005; Choi and Kim, 2006; Joly et al., 2006; Zhu et al., 2012; Li et al., 2014). ${ }^{\mathrm{C}}$ Zobrist et al. (2008); Tong et al. (2011). A density of $910 \mathrm{~kg} \mathrm{~m}^{-3}$ was used for all simulations as density was found to have no effect on simulated viscosities. ${ }^{\mathrm{d}}$ Contact angles were determined by photographing a series of five sucrose-water particles, each on a separate hydrophobic slide. The contact angle was measured at the particle-substrate interface of both the right and left edges of the particle using ImageJ software. The mean contact angle was determined to be $98.5^{\circ}$, and the lower and upper limits of contact angle were determined to be 94.8 and $102.2^{\circ}\left(98.5^{\circ} \pm 1 \sigma\right)$. The relationship between the simulated viscosity of a particle and its contact angle is dependent upon the dimensions of the particle, more specifically the value of the ratio $\left(R_{0}-r_{0}\right) / r_{0}$. The lower limit of contact angle gave rise to the lower limit of viscosity for particles where $\left(R_{0}-r_{0}\right) / r_{0}>2$, whilst the upper limit of contact angle gave rise to the upper limit of viscosity for particles where $\left(R_{0}-r_{0}\right) / r_{0}<2$.

ticles was too fast to measure. Lower and upper limits of viscosity were determined for each individual particle using their dimensions and $\tau_{\text {exp, flow }}$ (Fig. 4b). Between 59 and $36 \% \mathrm{RH}$, the viscosities for individual sucrose-water particles range from $1.0 \times 10^{1}$ to $6.6 \times 10^{6} \mathrm{Pas}$, with the upper limit of viscosity for a given particle being a factor of 16 to a factor of 140 larger than the corresponding lower limit of viscosity, with the uncertainty mainly due to the value of the physical properties used during simulations.

In Fig. 4c, the viscosities of individual particles are grouped by $\mathrm{RH}$, and previously reported values of the viscosity of sucrose-water particles are included for compari- 

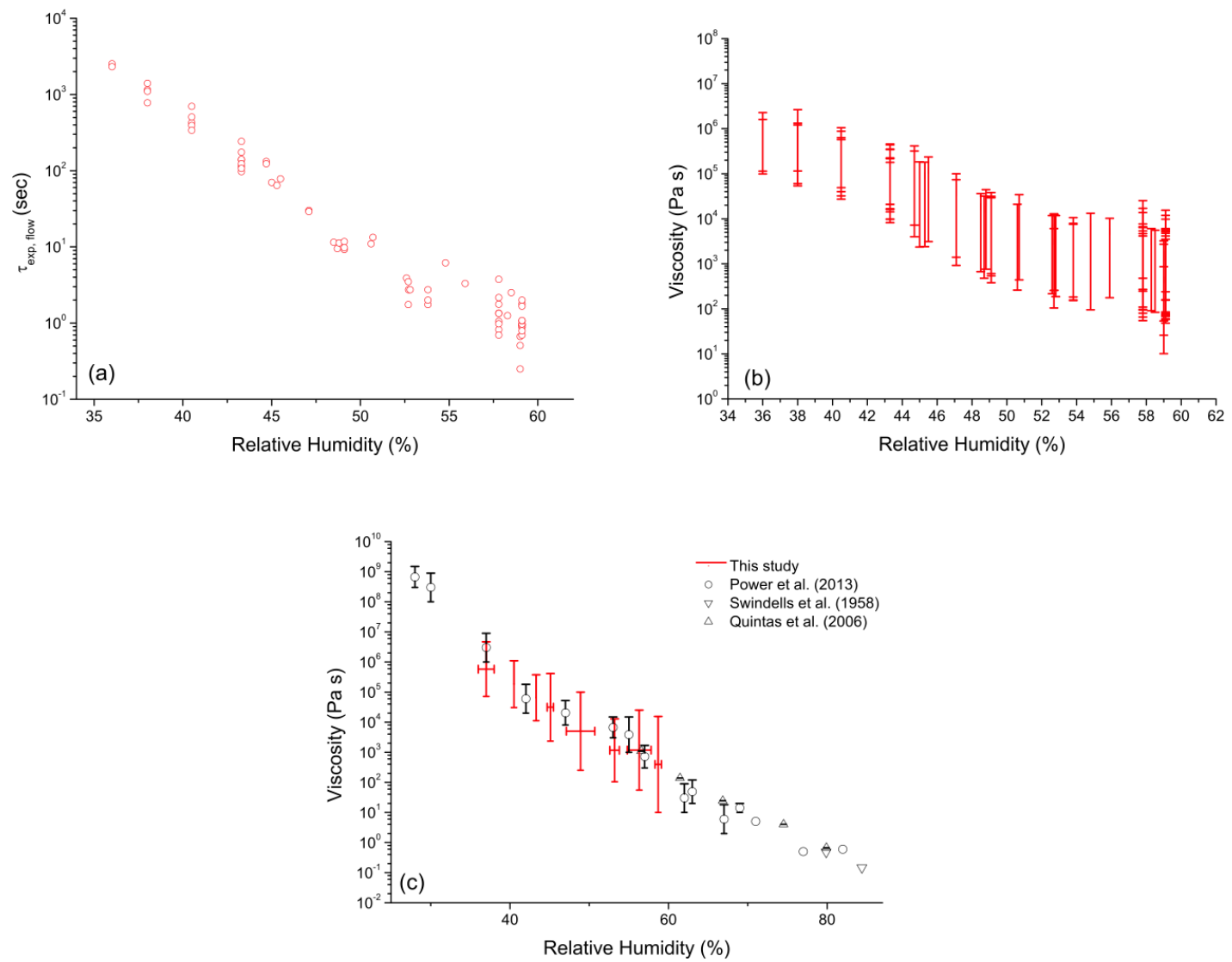

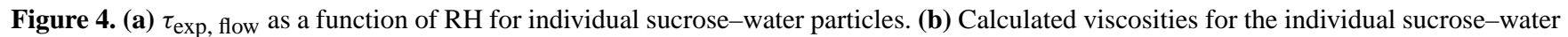
particles in (a), where red bars represent the calculated lower and upper limits of viscosity. (c) Lower and upper limits of viscosity for the particles shown in (b), grouped by RH. The error bars on the $x$ axis represent the range of RHs at which particles in the group were poked. Lower and upper limits of viscosity were determined for each particle via simulation, with the bottom of a bar on the $y$ axis representing the lowest lower limit of viscosity for any of the particles in the group, and the top of the bar representing the highest upper limit of viscosity for any of the particles in the group. Literature values (Swindells et al., 1958; Quintas et al., 2006; Power et al., 2013) are provided for comparison, with error bars representing $1 \sigma$ for Power et al. and $95 \%$ confidence intervals for Quintas et al.

Table 2. Experimental parameters used when simulating flow with COMSOL for experiments using polybutene standards.

\begin{tabular}{llllll}
\hline & $\begin{array}{l}\text { Surface tension } \\
\left(\mathrm{mN} \mathrm{m}^{-1}\right)\end{array}$ & $\begin{array}{l}\text { Slip length } \\
(\mathrm{m})\end{array}$ & $\begin{array}{l}\text { Density } \\
\left(\mathrm{kg} \mathrm{m}^{-3}\right)\end{array}$ & Standard \#1 (N450000) & $\begin{array}{c}\text { Contact angle }\left(^{\circ}\right) \\
\text { Standard \#2 }(\mathrm{N} 2700000)\end{array}$ \\
\hline Range of values & $25-50^{\mathrm{a}}$ & $\begin{array}{l}5 \times 10^{-9}- \\
1 \times 10^{-5^{\mathrm{b}}}\end{array}$ & $\begin{array}{l}910- \\
913^{\mathrm{c}}\end{array}$ & $\begin{array}{l}53.6- \\
66.4^{\mathrm{d}}\end{array}$ & $\begin{array}{l}48.8- \\
57.4^{\mathrm{d}}\end{array}$ \\
\hline $\begin{array}{l}\text { Value used to calculate } \\
\text { lower limit of viscosity }\end{array}$ & 25 & $5 \times 10^{-9}$ & 910 & $\begin{array}{l}53.6 \text { for particles of }\left(R_{0}-r_{0}\right) / r_{0}<2 \\
66.4 \text { for particles of }\left(R_{0}-r_{0}\right) / r_{0}<2\end{array}$ & $\begin{array}{l}48.8 \text { for particles of }\left(R_{0}-r_{0}\right) / r_{0}<2 \\
57.4 \text { for particles of }\left(R_{0}-r_{0}\right) / r_{0}>2\end{array}$ \\
\hline $\begin{array}{l}\text { Value used to calculate } \\
\text { upper limit of viscosity }\end{array}$ & 50 & $1 \times 10^{-5}$ & 910 & $\begin{array}{l}66.4 \text { for particles of }\left(R_{0}-r_{0}\right) / r_{0}<2 \\
53.6 \text { for particles of }\left(R_{0}-r_{0}\right) / r_{0}>2\end{array}$ & $\begin{array}{l}53.6 \text { for particles of }\left(R_{0}-r_{0}\right) / r_{0}<2 \\
66.4 \text { for particles of }\left(R_{0}-r_{0}\right) / r_{0}>2\end{array}$ \\
\hline
\end{tabular}

a Five studies have examined the surface tension of the polybutene, with the reported values ranging from 29 to $34.3 \mathrm{mN} \mathrm{m}^{-1}$ (Roe, 1968; Jeong and Moffatt, 1992; Lewandowski and Dupuis, 1994; Blunk and Wilkes, 2001; Mewis and Metzner, 2006). As the polybutene standards studied here are unlikely to differ much from those studied elsewhere, a conservative value of $25 \mathrm{mN} \mathrm{m}^{-1}$ has been used as the lower limit of surface tension. Blunk and Wilkes (2001) studied three different polybutene resins of differing viscosities. Measured surface tension values suggested a direct, though weak, relationship between surface tension and viscosity (surface tension increased from 29.3 to $30.0 \mathrm{mN} \mathrm{m}^{-1}$ as the viscosity of the resins increased from 4 to 16.4 Pa s). As the resins studied by Blunk and Wilkes (2001) were 2 orders of magnitude less viscous than those measured herein, a conservative upper estimate of $50 \mathrm{mN} \mathrm{m}^{-1}$ has been used in simulations for the surface tension of the polybutene standards. ${ }^{\text {b }}$ This range is based on experimental measurements of the slip length of water and organic compounds on hydrophobic surfaces (Schnell, 1956; Churaev et al., 1984; Watanabe and Udagawa, 1999; Baudry et al., 2001; Craig et al., 2001; Tretheway and Meinhart, 2002; Cheng and Giordano, 2002; Jin et al., 2004; Joseph and Tabeling, 2005; Neto et al., 2005; Choi and Kim, 2006; Joly et al., 2006; Zhu et al., 2012; Li et al., 2014). ${ }^{\mathrm{c}}$ Measured by Cannon Instrument Company. A density of $910 \mathrm{~kg} \mathrm{~m}^{-3}$ was used for all simulations as density was found to have no effect on simulated viscosities. ${ }^{\mathrm{d}}$ Contact angles were determined as for sucrose-water particles (Table 1). For standard \#1 (N450000) the lower and upper limits of contact angle were determined to be 53.6 and $66.4^{\circ}$ (i.e. $60.0^{\circ} \pm 1 \sigma$ ), whilst for standard \#2 (N2700000) the lower and upper limits of contact angle were determined to be 48.8 and $57.4^{\circ}$ (i.e. $53.1^{\circ} \pm 1 \sigma$ ) 


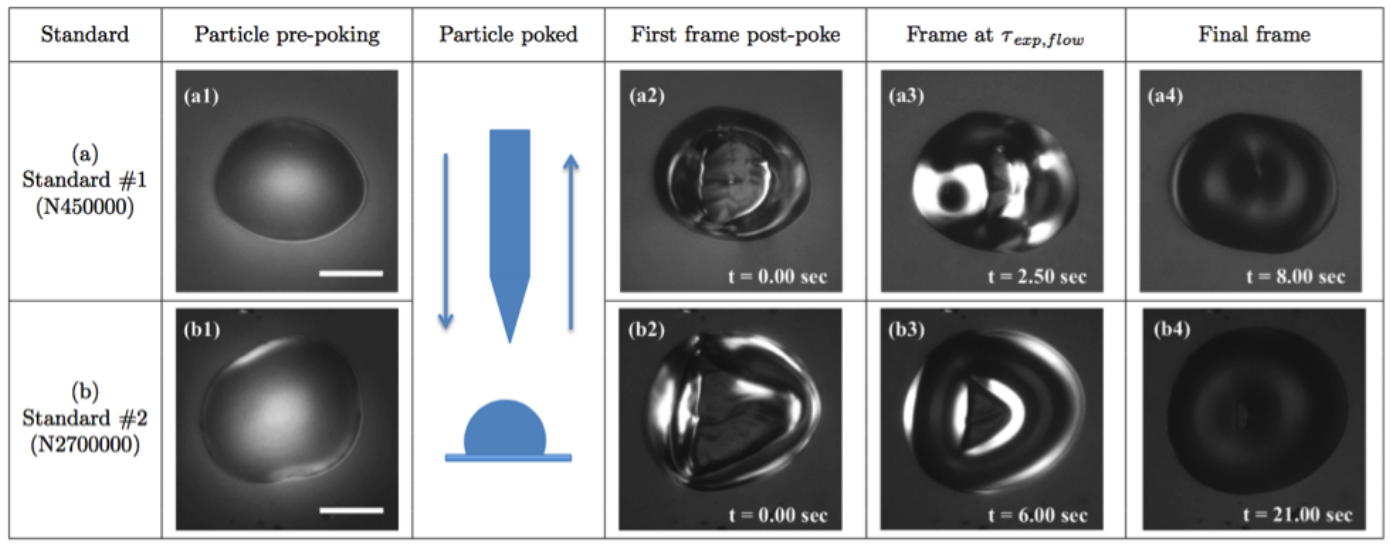

Figure 5. Optical images of particles of polybutene standards, (a) standard \#1 (N450000) and (b) standard \#2 (N2700000), being poked at $0 \% \mathrm{RH}$ recorded during typical poke-flow experiments. Images a1 and b1 correspond to particles prior to poking. Images a2 and b2 correspond to the first frame post-poke (i.e. the first frame after the needle has been removed). Images a3 and b3 correspond to images of the experimental flow time, $\tau_{\exp }$, flow , the point at which the equivalent area diameter of the hole at the centre of the torus has decreased to $50 \%$ of its original size. Images a4 and b4 correspond to the final frame recorded of each particle, at which point each particle has re-attained its original spherical cap geometry. Size bar: $20 \mu \mathrm{m}$.

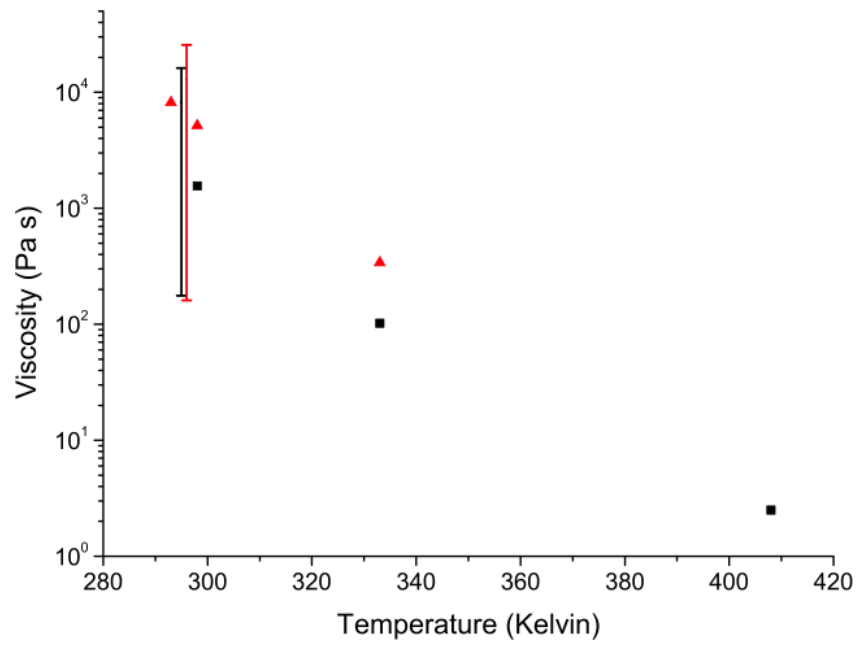

Figure 6. Viscosity as a function of temperature for experiments with the polybutene standards. Results from standard \#1 (N450000) are in black, whilst results from standard \#2 (N2700000) are in red. Symbols represent values measured by Cannon Instrument Company using a manual capillary viscometer. Bars represent viscosities determined herein. For the bar that represents each standard the bottom of the bar represents the lowest lower limit of viscosity of all the particles examined, whilst the top of the bar represents the highest upper limit of viscosity of all of the particles examined.

son (Swindells et al., 1958; Quintas et al., 2006; Power et al., 2013). Viscosities have been determined by grouping particles based upon RH, with lower and upper limits of viscosity from particles in the group reported. The lower and upper limits of viscosity of the group of particles poked at $\approx 59 \%$ $\mathrm{RH}$ are $1.0 \times 10^{1}$ and $1.6 \times 10^{4} \mathrm{Pas}$, whilst at $37 \% \mathrm{RH}$ the corresponding values are $7.2 \times 10^{4}$ and $4.7 \times 10^{6} \mathrm{Pas}$, re- spectively. As shown in Fig. 4c, the results are in good agreement with Quintas et al. (2006), who measured a viscosity of $10^{3} \mathrm{Pas}$ at $54 \% \mathrm{RH}$ using a rotational controlled stress rheometer, and with Power et al. (2013), who recently reported mean measured viscosities of $\approx 5 \times 10^{2}$ to $\approx 3 \times 10^{6} \mathrm{~Pa}$ s between 60 and $37 \% \mathrm{RH}$ using holographic optical tweezers.

\subsection{Particles of polybutene standards}

Figure 5 shows examples of optical images of particles of the polybutene standards recorded during poke-flow experiments at $0 \% \mathrm{RH}$. As for sucrose-water particles, the geometry of the particles of standard solution could be described as a spherical cap prior to being poked (Fig. 5a1 and b1) and a half-torus after being poked (Fig. $5 \mathrm{a} 2$ and b2). Upon removal of the needle the material flowed, with the size of the hole at the centre of the half-torus geometry decreasing over time. For the particles in Fig. 5 , $\tau_{\text {exp } \text {, flow was de- }}$ termined to be 2.50 and $6.00 \mathrm{~s}$, respectively (Fig. $5 \mathrm{a} 3$ and b3). The particle continued to flow after $\tau_{\text {exp } \text {, flow and eventu- }}$ ally re-attained its initial, energetically favourable, spherical cap geometry (Fig. 5a4 and b4). The mean experimental flow

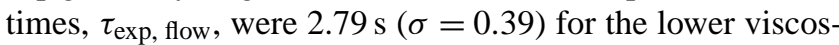
ity standard \#1 and $7.86 \mathrm{~s}(\sigma=1.65)$ for the higher viscosity standard \#2.

As done in the sucrose-water experiments, $\tau_{\text {exp, flow }}$ values from individual particles were converted into viscosities using simulations. To determine upper and lower limits for the viscosities of the standards, we took the upper and lower limits of the viscosities determined from the individual particles. Using this approach and the parameters listed in Table 2, the simulated lower and upper limits of viscosity for the particles poked were $2.0 \times 10^{2}$ and $1.2 \times 10^{4} \mathrm{~Pa}$ s for standard \#1 
(N450000), and $3.1 \times 10^{2}$ and $2.4 \times 10^{4} \mathrm{~Pa}$ s for standard \#2 (N2700000). These values are in good agreement with value reported by the manufacturer, Cannon Instrument Company (see Fig. 6).

\section{Summary}

The poke-flow technique combined with simulations of fluid flow provides the advantage of being able to measure viscosities of samples that are both highly viscous and available only in small sample volumes. The combination of these characteristics provides a challenge that is beyond the reach of current commercially available viscometers. In RenbaumWolff et al. (2013a), only a preliminary validation of the poke-flow technique combined with simulations of fluid flow was carried out for viscosities up to $10^{4} \mathrm{~Pa}$, due to the lack of suitable standards for validation at the time of publication. The current manuscript expands on the initial validation experiments by Renbaum-Wolff et al. (2013a). First, the approach was used to determine the viscosity of sucrosewater particles over a wider range of RHs than previously done by Renbaum-Wolff et al. (2013a). The lower and upper limits of viscosity at $\approx 59 \% \mathrm{RH}$ were $1.0 \times 10^{1}$ and $1.6 \times 10^{4} \mathrm{Pas}$, whilst at $37 \% \mathrm{RH}$ the corresponding values were $7.2 \times 10^{4}$ and $4.7 \times 10^{6} \mathrm{Pas}$, respectively. The results are in good agreement with Quintas et al. (2006), who measured a viscosity of $10^{3} \mathrm{Pas}$ at $54 \% \mathrm{RH}$ using a rotational controlled stress rheometer, and with Power et al. (2013), who recently reported that measured mean viscosities of $\approx 5 \times 10^{2}$ to $\approx 3 \times 10^{6} \mathrm{~Pa}$ s between 60 and $37 \% \mathrm{RH}$ using holographic optical tweezers.

Second, the approach was used to determine the viscosity of two polybutene standards. The simulated lower and upper limits of viscosity for standard \#1 was $2.0 \times 10^{2}$ and $1.6 \times 10^{4} \mathrm{Pas}$, and for standard \#2 $1.6 \times 10^{2}$ and $2.6 \times 10^{4} \mathrm{~Pa}$. These values are in good agreement with values reported by Cannon Instrument Company (see Fig. 6).

The results for both the sucrose-water particles and the polybutene standards show the poke-flow technique combined with simulations of fluid flow is capable of providing both lower and upper limits of viscosity that are consistent with literature or measured values when the viscosity is in the range of $\approx 5 \times 10^{2}$ to $\approx 3 \times 10^{6} \mathrm{~Pa}$. This covers an important part of the range of viscosities of secondary organic material generated in environmental chambers. For example, this range of viscosities has been measured at atmospherically relevant RHs for both the water-soluble fraction of the SOM produced via the ozonolysis of $\alpha$-pinene (RenbaumWolff et al., 2013a) and the total SOM produced via that of isoprene (Song et al., 2015). In addition, this technique has several advantages, including being low in cost and the experimental setup affording compatibility with cascade impactors for particle collection.
Whilst the poke-flow technique combined with simulations of fluid flow gives good agreement with measured values, the upper limit of viscosity for a given particle is typically a factor of 16-140 larger than the corresponding lower limit of viscosity. Thus, the limits of viscosity determined using this approach are wide. The largest source of uncertainty in the approach is the values of surface tension and slip length used in the simulations. Constraining these values could lead to a reduction in the uncertainty of the measurements.

Acknowledgements. We thank the Natural Science and Engineering Research Council of Canada for funding and the Laboratory for Advanced Spectroscopy and Imaging Research facility at the University of British Columbia for use of the microscope used in these experiments.

Edited by: F. Pope

\section{References}

Baltensperger, U., Dommen, J., Alfarra, M. R., Duplissy, J., Gaeggeler, K., Metzger, A., Facchini, M. C., Decesari, S., Finessi, E., Reinnig, C., Schott, M., Warnke, J., HOFFMANN, T., Klatzer, B., Puxbaum, H., Geiser, M., Savi, M., Lang, D., Kalberer, M., and Geiser, T.: Combined Determination of the Chemical Composition and of Health Effects of Secondary Organic Aerosols: The POLYSOA Project, J. Aerosol. Med. Pulm. Drug. Deliv., 21, 145-154, 2008.

Baudry, J., Charlaix, E., Tonck, A., and Mazuyer, D.: Experimental Evidence for a Large Slip Effect at a Nonwetting Fluid-Solid Interface, Langmuir, 17, 5232-5236, 2001.

Blunk, R. and Wilkes, J. O.: Surface-tension-driven flows of coatings: Bondline readout formation - Springer, J. Coating. Tech., 73, 63-71, doi:10.1007/Bf02698025, 2001.

Cheng, J. T. and Giordano, N.: Fluid flow through nanometer-scale channels, Phys. Rev. E., 65, 031206, doi:10.1103/PhysRevE.65.031206, 2002.

Choi, C.-H. and Kim, C.-J.: Large Slip of Aqueous Liquid Flow over a Nanoengineered Superhydrophobic Surface, Phys. Rev. Lett., 96, 066001, doi:10.1103/PhysRevLett.96.066001, 2006.

Churaev, N. V., Sobolev, V. D., and Somov, A. N.: Slippage of liquids over lyophobic solid surfaces, J. Coll. Inter. Sci., 97, 574$581,1984$.

Craig, V. S., Neto, C., and Williams, D. R.: Shear-dependent boundary slip in an aqueous Newtonian liquid., Phys. Rev. Lett., 87, 054504, doi:10.1103/Physrevlett.87.054504, 2001.

Hosny, N. A., Fitzgerald, C., Tong, C., Kalberer, M., Kuimova, M. K., and Pope, F. D.: Fluorescent lifetime imaging of atmospheric aerosols: a direct probe of aerosol viscosity, Faraday Discuss., 165, 343-356, doi:10.1039/c3fd00041a, 2013.

Jang, M., Ghio, A. J., and Cao, G.: Exposure of BEAS-2B cells to secondary organic aerosol coated on magnetic nanoparticles., Chem. Res. Toxicol., 19, 1044-1050, 2006.

Jeong, J. T. and Moffatt, H. K.: Free-surface cusps associated with flow at low Reynolds number, J. Fluid Mechan., 241, 1-22, 1992.

Jimenez, J. L., Canagaratna, M. R., Donahue, N. M., Prevot, A. S. H., Zhang, Q., Kroll, J. H., DeCarlo, P. F., Allan, J. D., Coe, 
H., Ng, N. L., Aiken, A. C., Docherty, K. S., Ulbrich, I. M., Grieshop, A. P., Robinson, A. L., Duplissy, J., Smith, J. D., Wilson, K. R., Lanz, V. A., Hueglin, C., Sun, Y. L., Tian, J., Laaksonen, A., Raatikainen, T., Rautiainen, J., Vaattovaara, P., Ehn, M., Kulmala, M., Tomlinson, J. M., Collins, D. R., Cubison, M. J., Dunlea, E. J., Huffman, J. A., Onasch, T. B., Alfarra, M. R., Williams, P. I., Bower, K., Kondo, Y., Schneider, J., Drewnick, F., Borrmann, S., Weimer, S., Demerjian, K., Salcedo, D., Cottrell, L., Griffin, R., Takami, A., Miyoshi, T., Hatakeyama, S., Shimono, A., Sun, J. Y., Zhang, Y. M., Dzepina, K., Kimmel, J. R., Sueper, D., Jayne, J. T., Herndon, S. C., Trimborn, A. M., Williams, L. R., Wood, E. C., Middlebrook, A. M., Kolb, C. E., Baltensperger, U., and Worsnop, D. R.: Evolution of organic aerosols in the atmosphere., Science (New York, N.Y.), 326, 1525-1529, 2009.

Jin, S., Huang, P., Park, J., Yoo, J. Y., and Breuer, K. S.: Nearsurface velocimetry using evanescent wave illumination, Experim. Fluids, 37, 825-833, 2004.

Joly, L., Ybert, C., and Bocquet, L.: Probing the nanohydrodynamics at liquid-solid interfaces using thermal motion, Phys. Rev. Lett., 96, 046101, doi:10.1103/Physrevlett.96.046101, 2006.

Joseph, P. and Tabeling, P.: Direct measurement of the apparent slip length, Phys. Rev. E, 71, 035303, doi:10.1103/Physreve.71.035303, 2005.

Kanakidou, M., Seinfeld, J. H., Pandis, S. N., Barnes, I., Dentener, F. J., Facchini, M. C., Van Dingenen, R., Ervens, B., Nenes, A., Nielsen, C. J., Swietlicki, E., Putaud, J. P., Balkanski, Y., Fuzzi, S., Horth, J., Moortgat, G. K., Winterhalter, R., Myhre, C. E. L., Tsigaridis, K., Vignati, E., Stephanou, E. G., and Wilson, J.: Organic aerosol and global climate modelling: a review, Atmos. Chem. Phys., 5, 1053-1123, doi:10.5194/acp-5-1053-2005, 2005.

Kidd, C., Perraud, V., Wingen, L. M., and Finlayson-Pitts, B. J.: Integrating phase and composition of secondary organic aerosol from the ozonolysis of $\alpha$-pinene, Proc. Natl. Acad. Sci. USA, 111, 7552-7557, 2014.

Koop, T., Kapilashrami, A., Molina, L. T., and Molina, M. J.: Phase transitions of sea-salt/water mixtures at low temperatures: Implications for ozone chemistry in the polar marine boundary layer, J. Geophys. Res., 105, 26393, doi:10.1029/2000JD900413, 2000.

Koop, T., Bookhold, J., Shiraiwa, M., and Pöschl, U.: Glass transition and phase state of organic compounds: dependency on molecular properties and implications for secondary organic aerosols in the atmosphere, Phys. Chem. Chem. Phys., 13, 19238-19255, 2011.

Kuwata, M. and Martin, S. T.: Phase of atmospheric secondary organic material affects its reactivity, Proc. Natl. Acad. Sci. USA, 109, 17354-17359, 2012.

Lewandowski, F. Y. and Dupuis, D.: Dynamic measurements of surface tension of solutions of polyisobutylene in mixtures of polybutene oil and Decalin, J. Non-Newton. Fluid, 52, 233-248, 1994.

Li, D. Y., Jing, D. L., Pan, Y. L., and Ahmad, K.: Slip Length Measurement of Water Flow on Graphite Surface Using Atomic Force Microscope, Adv. Material. Res., 941-944, 1581-1584, 2014.

MacDonald, G. A., Lanier, T. C., Swaisgood, H. E., and Hamann, D. D.: Mechanism for Stabilization of Fish Actomyosin by Sodium Lactate, J. Agricul. Food Chem., 44, 106-112, 1996.
Mewis, J. and Metzner, A. B.: The rheological properties of suspensions of fibres in Newtonian fluids subjected to extensional deformations, J. Fluid Mechan., 62, 593-600, doi:10.1017/S0022112074000826, 2006.

Murray, B. J., Wilson, T. W., Dobbie, S., Cui, Z., Al-Jumur, S. M. R. K., Möhler, O., Schnaiter, M., Wagner, R., Benz, S., Niemand, M., Saathoff, H., Ebert, V., Wagner, S., and Kärcher, B.: Heterogeneous nucleation of ice particles on glassy aerosols under cirrus conditions, Nat. Geosci., 3, 233-237, 2010.

Murray, B. J., Haddrell, A. E., Peppe, S., Davies, J. F., Reid, J. P., O'Sullivan, D., Price, H. C., Kumar, R., Saunders, R. W., Plane, J. M. C., Umo, N. S., and Wilson, T. W.: Glass formation and unusual hygroscopic growth of iodic acid solution droplets with relevance for iodine mediated particle formation in the marine boundary layer, Atmos. Chem. Phys., 12, 8575-8587, doi:10.5194/acp-12-8575-2012, 2012.

Neto, C., Evans, D. R., Bonaccurso, E., Butt, H.-J., and Craig, V. S. J.: Boundary slip in Newtonian liquids: a review of experimental studies, Reports Prog. Phys., 68, 2859-2897, 2005.

Pajunoja, A., Malila, J., Hao, L., Joutsensaari, J., Lehtinen, K. E. J., and Virtanen, A.: Estimating the Viscosity Range of SOA Particles Based on Their Coalescence Time, Aerosol Sci. Tech., 48, i-iv, 2014.

Perraud, V., Bruns, E. A., Ezell, M. J., Johnson, S. N., Yu, Y., Alexander, M. L., Zelenyuk, A., Imre, D., Chang, W. L., Dabdub, D., Pankow, J. F., and Finlayson-Pitts, B. J.: Nonequilibrium atmospheric secondary organic aerosol formation and growth., Proc. Natl. Acad. Sci. USA, 109, 2836-2841, 2012.

Power, R. M. and Reid, J. P.: Probing the micro-rheological properties of aerosol particles using optical tweezers, Reports Prog. Phys., 77, 074601, doi:10.1088/0034-4885/77/7/074601, 2014.

Power, R. M., Simpson, S. H., Reid, J. P., and Hudson, A. J.: The transition from liquid to solid-like behaviour in ultrahigh viscosity aerosol particles, Chem. Sci., 4, 2597-2604, 2013.

Quintas, M., Brandão, T. R. S., Silva, C. L. M., and Cunha, R. L.: Rheology of supersaturated sucrose solutions, J. Food Eng., 77, 844-852, 2006.

Reist, P.: Aerosol Science and Technology, McGraw-Hill Professional, New York, NY, USA, 2 Edn., 1992.

Renbaum-Wolff, L., Grayson, J. W., Bateman, A. P., Kuwata, M., Sellier, M., Murray, B. J., Shilling, J. E., Martin, S. T., and Bertram, A. K.: Viscosity of $\alpha$-pinene secondary organic material and implications for particle growth and reactivity., Proc. Natl. Acad. Sci. USA, 110, 8014-8019, 2013 a.

Renbaum-Wolff, L., Grayson, J. W., and Bertram, A. K.: Technical Note: New methodology for measuring viscosities in small volumes characteristic of environmental chamber particle samples, Atmos. Chem. Phys., 13, 791-802, doi:10.5194/acp-13791-2013, 2013b.

Riipinen, I., Pierce, J. R., Yli-Juuti, T., Nieminen, T., Häkkinen, S., Ehn, M., Junninen, H., Lehtipalo, K., Petäjä, T., Slowik, J., Chang, R., Shantz, N. C., Abbatt, J., Leaitch, W. R., Kerminen, V.-M., Worsnop, D. R., Pandis, S. N., Donahue, N. M., and Kulmala, M.: Organic condensation: a vital link connecting aerosol formation to cloud condensation nuclei $(\mathrm{CCN})$ concentrations, Atmos. Chem. Phys., 11, 3865-3878, doi:10.5194/acp-11-38652011, 2011.

Riipinen, I., Yli-Juuti, T., Pierce, J. R., Petäjä, T., Worsnop, D. R., Kulmala, M., and Donahue, N. M.: The contribution of organics 
to atmospheric nanoparticle growth, Nat. Geosci., 5, 453-458, 2012.

Roe, R.-J.: Surface tension of polymer liquids, J. Phys. Chem., 72, 2013-2017, 1968.

Schnell, E.: Slippage of Water over Nonwettable Surfaces, J. Appl. Phys., 10, 1149-1152, 1956.

Shiraiwa, M. and Seinfeld, J. H.: Equilibration timescale of atmospheric secondary organic aerosol partitioning, Geophys. Res. Lett., 39, L24801, doi:10.1029/2012g1054008, 2012.

Shiraiwa, M., Ammann, M., Koop, T., and Pöschl, U.: Gas uptake and chemical aging of semisolid organic aerosol particles, Proc. Natl. Acad. Sci. USA, 108, 11003-11008, 2011.

Shiraiwa, M., Zuend, A., Bertram, A. K., and Seinfeld, J. H.: Gasparticle partitioning of atmospheric aerosols: interplay of physical state, non-ideal mixing and morphology, Phys. Chem. Chem. Phys., 15, 11441-11453, 2013.

Solomon, S., Qin, D., Manning, M., Alley, R. B., Bernsten, T., Bindoff, N. L., Chen, Z., Chidthaisong, A., Gregory, J. M., GC, H., Heimann, M., Hewiston, B., Hoskins, B. J., Joos, F., Jouzel, J., Kattsov, V., Lohmann, U., Matsuno, T., Molina, M., Nicholls, N., Overpeck, J., Raga, G., Ramaswamy, V., Ren, J., Rusticucci, M., Somerville, R., Stocker, T. F., Whetton, P., Wood, R. A., and Wratt, D.: Technical Summary, in: Climate Change 2007: The Physical Science Basis. Contribution of Working Group I to the Fourth Assessment Report of the Intergovernmental Panel on Climate Change, edited by: Solomon, S., Qin, D., Manning, M., Chen, Z., Marquis, M., Averyt, K. B., Tignor, M., and Miller, H. L., Cambridge University Press, Cambridge, United Kingdom and New York, NY, USA, 996 pp., 2007.

Song, M., Marcolli, C., Krieger, U. K., Zuend, A., and Peter, T.: Liquid-liquid phase separation and morphology of internally mixed dicarboxylic acids/ammonium sulfate/water particles, Atmos. Chem. Phys., 12, 2691-2712, doi:10.5194/acp-12-26912012, 2012.

Song, M., Liu, P. F., Hanna, S. J., Li, Y. J., Martin, S. T., and Bertram, A. K.: Relative humidity-dependent viscosities of isoprene-derived secondary organic material and atmospheric implications for isoprene-dominant forests, Atmos. Chem. Phys., 15, 5145-5159, doi:10.5194/acp-15-5145-2015, 2015.
Swindells, J. F., Snyder, C. F., Hardy, R. C., and Golden, P. E.: Viscosities of Sucrose Solutions at Various Temperatures: Tables of Recalculated Values, United States Department of Commerce, 1958.

Tong, H. J., Reid, J. P., Bones, D. L., Luo, B. P., and Krieger, U. K.: Measurements of the timescales for the mass transfer of water in glassy aerosol at low relative humidity and ambient temperature, Atmos. Chem. Phys., 11, 4739-4754, doi:10.5194/acp-11-47392011, 2011.

Tretheway, D. C. and Meinhart, C. D.: Apparent fluid slip at hydrophobic microchannel walls, Phys. Fluids, 14, L9-L12, 2002.

Wang, B., Lambe, A. T., and Massoli, P.: The deposition ice nucleation and immersion freezing potential of amorphous secondary organic aerosol: Pathways for ice and mixedphase cloud formation, J. Geophys. Res., 117, D16209, doi:10.1029/2012JD018063, 2012.

Watanabe, K. and Udagawa, Y.: Drag reduction of Newtonian fluid in a circular pipe with a highly water-repellent wall, J. Fluid Mechan., 381, 225-238, 1999.

You, Y., Renbaum-Wolff, L., Carreras-Sospedra, M., Hanna, S. J., Hiranuma, N., Kamal, S., Smith, M. L., Zhang, X., Weber, R. J., Shilling, J. E., Dabdub, D., Martin, S. T., and Bertram, A. K.: Images reveal that atmospheric particles can undergo liquid-liquid phase separations, Proc. Natl. Acad. Sci. USA, 109, 1318813193, 2012.

Zelenyuk, A., Imre, D., Beránek, J., Abramson, E., Wilson, J., and Shrivastava, M.: Synergy between secondary organic aerosols and long-range transport of polycyclic aromatic hydrocarbons, Environ. Sci. Technol., 46, 12459-12466, 2012.

Zhou, S., Shiraiwa, M., McWhinney, R. D., Pöschl, U., and Abbatt, J. P. D.: Kinetic limitations in gas-particle reactions arising from slow diffusion in secondary organic aerosol, Faraday Discuss., 165, 391-406, 2013.

Zhu, L., Attard, P., and Neto, C.: Reconciling slip measurements in symmetric and asymmetric systems, Langmuir, 28, 7768-7774, 2012.

Zobrist, B., Marcolli, C., Pedernera, D. A., and Koop, T.: Do atmospheric aerosols form glasses?, Atmos. Chem. Phys., 8, 52215244, doi:10.5194/acp-8-5221-2008, 2008. 